\title{
Journal of Physics and Its Applications
}

\author{
Journal homepage :https://ejournal2.undip.ac.id/index.php/jpa/index
}

\section{Calculation of Absorption Dose Value using MIRD Method with Cobalt 57 MIBI for Four Body Organs}

\author{
Asep Yoyo Wardaya ${ }^{1,2 *}$, Wahyu Setia Budi ${ }^{1}$, Ali Khumaeni ${ }^{1}$, Choirul Anam ${ }^{1}$ and Gani Gunawan ${ }^{3}$ \\ ${ }^{1}$ Department of Physics, Faculty of Science and Mathematics, Diponegoro University, Semarang Indonesia \\ ${ }^{2}$ Master Program of Energy, School of Post Graduate Studies, Diponegoro University, Semarang Indonesia \\ ${ }^{3}$ Department of Nuclear Medicine, Kariadi General Hospital School of Medicine, Diponegoro University, Semarang Indonesia
}

\section{A R T I C LE IN F O}

\section{Article history:}

Received : 28 October 2019

Accepted : 27 November 2019

Available online : 30 November 2019

\section{Keywords:}

MIRD

Cobalt 57

absorption dose

thyroid

kidney

\begin{abstract}
A B S T R A C T
The Medical Internal Radiation Dosimetry (MIRD) has developed methods, assumptions, models, and mathematical formulae for estimating internal radiation doses from the injected radiopharmaceuticals into the body. This study aims to determine the radiopharmaceutical distribution of Cobalt 57 MIBI in four organs of patients identified as having breast cancer with the MIRD method with time variations. The four organs are the heart, thyroid, kidney, and liver. The absorption dose of each organ was calculated as the product of the cumulative activity and the $S$ factor of each organ. The results showed that the highest uptake dose in these patients was in the thyroid and kidney organs, and then followed by the heart and liver. These results indicate that the thyroid and kidney organs are the most vulnerable organs due to injection of radiopharmaceutical into the body of breast cancer patients.
\end{abstract}

\section{Introduction}

Nuclear medicine has been used to diagnose many diseases and to treat many cases of cancers. In the nuclear medicine, radiopharmaceuticals are injected into the patient body. Injection of radiopharmaceuticals into the body allows those substances to be uniformly or non-uniformly distributed in organs and they will then emit radiation. The radiation released by the distributed radiopharmaceuticals in the organs is used for detecting abnormality inside the body or used to kill the cancers, depending on the type and dose of the radiation. The organ emitting the radiation is called as the source organs (s), and the organ absorbing the radiation is called the target organs $(t)$. The fraction of radiation distributed and absorbed by the organs differs for each organ. In fact, the source organ can also be a target organ. It means that some organs perform well as both source and target. These include the heart, kidneys, thyroid, and liver. There are also organs that perform poorly as either source or target. An example of this is the breasts that do not effectively emit or absorb radiopharmaceutical doses. This means that radiopharmaceutical activities in the breasts are too small, and hence, they are neglected.

An estimation of the dose absorbed by the organ is crucial for both diagnosis and therapy. However, the estimation of the absorbed by the organ is very complex. Many parameters influence to the dose distribution inside the body: physically, chemically, and biologically. Radiation estimation is essential for risk assessment, radiation protection, and treatment planning for treatment of cancer. The Medical Internal Radiation Dosimetry (MIRD) Committeeofthe Society of Nuclear Medicine (SNR) has developed methods, assumptions, models, and mathematical formulae for estimating internal radiation doses from the injected radiopharmaceuticals into the body [1]. The method is useful for estimating the radiation dose to the selected organs or all organs or the whole body from the injected radionuclides.

One of the biggest causes of death in women is breast cancer, which can spread to women in the young and old age categories. The breast cancer cells can spread to other organs in the human body such as the lungs, bones, liver, etc. One of the ways to diagnose the spread of breast cancer cells in organs such as the lungs, liver, etc, is through injection of radiopharmaceutical with MIBI (Methoxyisobutylisonitrile) carrier substances [2].

The radiopharmaceutical injected into the patient's body has a high activity, around $15-20 \mathrm{mCi}$. Thus, monitoring of internal doses in the patient's body is needed to ensure the level of safety and fulfillment of the dose optimization [2]. Distribution of activities of the radiopharmaceutical in the bloodstream after being injected into the patient's body is measured using an open compartment system model [3]. radiopharmaceutical that is injected into the blood will then enter the heart. From the heart, this substance is transferred to the organs of thyroid and breasts. However, the substance that reaches the breasts is not effectively absorbed. It just passes the breasts and goes straight to both the kidney and liver. Combination of radiopharmaceutical emitted from the kidneys and liver will meet the radiopharmaceutical coming from the thyroid. Finally, all pharmaceutical will end at the excretion. 
Previous studieson the calculation of the value of internal doses in various body organs were carried out. Suryanti[4] calculated the internal dose values in various bone-scan examination organsof Tc99mMDP MIBI by using the MIRD method. Hidayati et. al [5]calculated the dose distribution of ${ }^{177} \mathrm{Lu}-\mathrm{DOTA}$ TRASTUZUMAB radiopharmaceutical using the MIRD method. In this study, the S value was obtained using OLINDA / EXM software. Subsequent research was carried out by Hersela et. al. [6].The calculation of the internal dose value of 4 organs including the heart, thyroid, liver and kidney from injection of Tc99m MIBI with time variation was performed using the MIRD method. In the previous studies, the S value was obtained through MIRD table no. 11 [7].

This study aims to determine the radiopharmaceutical distribution of Cobalt 57 MIBI in 4 organs of patients identified as having breast cancer with MIRD method with time variations. The four organs of the patient's body are the heart, thyroid, kidney, and liver.

\section{Overview of The MIRD Method}

Calculation of the internal doses value of four organ components consisting of the heart, thyroid, kidney, and liver is done using the MIRD method. The value of total dose rate for the four organs $(i=1,2,3,4)$ can be written as follows [3],

$$
\dot{D}=\sum_{i} \dot{D}_{i}(t)=A_{s}(t) \sum_{i} \frac{\Delta_{i} \varphi_{i}}{m}
$$

where $\Delta_{\mathrm{i}}$ is the radiation value of the $i$ organ type emitted, $\varphi_{\mathrm{i}}$ isvalues of specific absorption fraction, $m$ is a mass of targetandtotal activity $A_{s}(\mathrm{t})$ as a function of time defined as [1],

$$
A_{s}(t)=A_{0} e^{-t\left(\lambda+\lambda_{j}\right)}
$$

with $A_{0}$ showing initial activity of the organ, while notations $\lambda$ and $\lambda_{j}$ are effective removal rates for both physical and biological cases respectively. They also relate to effective time of radiopharmaceutical activities as [1],

$$
\lambda+\lambda_{j}=\lambda_{\text {eff }}=\frac{\ln 2}{\left(T_{e f f}\right)} .
$$

The value of absorbed dose for MIRD of an organ can be calculated by integrating equation (1) from time $t$ $=0$ to time $t=\infty$, which is [8],

$$
D=\int_{0}^{\infty} A_{s}(t) d t \sum_{i} \Delta_{i} \phi_{i}\left(r_{s} \leftarrow r_{t}\right)=\tilde{A} \cdot S(s \leftarrow t)
$$

Where $\tilde{A}$ and $S$ are accumulative activities, and the $S$, respectively.This $S$ factor represent characteristics of radionuclide scattering, range of emitted radiation.

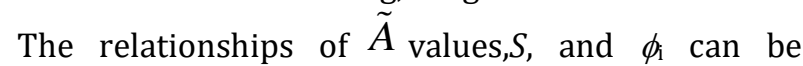
written with the following formula $[7,9]$,

$$
\begin{gathered}
\tilde{A}=\int_{0}^{\infty} A_{s}(t) d t \quad S(s \leftarrow t)=\sum_{i} \Delta_{i} \phi_{i}\left(r_{s} \leftarrow r_{t}\right) ; \\
\phi_{i}\left(r_{s} \leftarrow r_{t}\right)=\frac{\varphi_{i}}{m}
\end{gathered}
$$

Calculation for the value of $S$ for all body organs can

\begin{tabular}{|c|c|c|c|c|}
\hline \multirow{3}{*}{ Target Organ $(t)$} & \multicolumn{4}{|c|}{$S(\mathrm{rad} / \mu \mathrm{Ci}$-jam $)$} \\
\hline & \multicolumn{4}{|c|}{ Source Organ $(s)$} \\
\hline & $\begin{array}{l}\text { Heart } \\
\text { (1) }\end{array}$ & $\begin{array}{l}\text { Kidne } \\
\text { ys (2) }\end{array}$ & $\begin{array}{l}\text { Thyro } \\
\text { id (3) }\end{array}$ & $\begin{array}{l}\text { Liver } \\
\text { (4) }\end{array}$ \\
\hline \multirow[t]{2}{*}{ Heart (1) } & 9.58 & 1.32 & 6.84 & 7.39 \\
\hline & E-05 & E-06 & E-08 & E-07 \\
\hline \multirow{2}{*}{ Kidneys (2) } & 1.07 & 1.90 & 3.40 & 3.90 \\
\hline & E-06 & E-04 & E-08 & E-06 \\
\hline \multirow[t]{2}{*}{ Thyroid (3) } & 6.72 & 4.80 & 2.30 & 1.50 \\
\hline & E-07 & E-08 & E-03 & E-07 \\
\hline \multirow[t]{2}{*}{ Liver (4) } & 3.39 & 3.90 & 9.30 & 4.60 \\
\hline & E-06 & E-06 & E-08 & E-05 \\
\hline
\end{tabular}
be obtained from MIRD table no. 11 [7], as is shown for the case of the heart, kidneys, thyroid, and liver.

Table 1: Table for values of $S$ for 4 source and target organs consisting of the heart, kidneys, thyroid, and liver from MIRD table no. 11 [7].

In Table 1 , the $S$ factor is defined by the relationship of target organ $(t)$ and source organ $(s)$ from 4 body organs of the heart, kidneys, thyroid, and liver $(S$ value in Table 1 is a $4 \times 4$ matrix). For example, the target organ $(t)$ for kidneys (2) and source organ $(s)$ for thyroid (3) are in line 2 and column 3. Therefore, the value of $S$ factor from the target kidneys to the source thyroid is written as,

$$
S(s \leftarrow t)=S(3 \leftarrow 2)=3,40 \times 10^{-8} \mathrm{rad} / \mu \mathrm{Ci} \text {-jam. }
$$

From formulation (4), absorption dose for each organs of the heart, thyroid, kidneys, and liver is gained by multiplying the $S$ factor (shown in Table 1) with accumulative activities $\tilde{A}$. However, for the case of a set of body organs that relate to one another, formulation (4) for 4 different organs can be written as [7],

$$
D_{i}=\sum_{j=1}^{4} \tilde{A}_{j} S(i \leftarrow j)
$$

where $i, j=1,2,3$, and 4 , and each couple of $\left(\tilde{A}_{1}, D_{1}\right)$, $\left(\tilde{A}_{2}, D_{2}\right),\left(\tilde{A}_{3}, D_{3}\right)$ and $\left(\tilde{A}_{4}, D_{4}\right)$ are couples of accumulative activities and absorption dose for the heart (1), kidneys (2), thyroid (3), and liver (4), while $S(i \leftarrow j)$ is the value of $S$ from target organ $j$ to source $\operatorname{organ} i$. The value of activity $A$ in some of these organs can be calculated using equations

$$
A=\text { count } . C F \text {, }
$$

With $C F$ is a correction factor that depends on the method and type of dose used in the research. If the unit value of $A$ is in $\mathrm{mCi}$, then the unit value of $C F$ is in $\mathrm{mCi} /$ count. The cumulative activity value can be written as

$$
\tilde{A}(t)=A \cdot \tau=(\text { count } . \tau) . C F
$$

With $\tau$ is the radiopharmaceutical residence time in the body. The value of accumulative activity per unit correction factor is defined as the multiplication of count and residence time,

$$
T=\frac{\tilde{A}(t)}{C F}=\text { count } \times \tau,
$$

In this paper, we use the calculation of the accumulative activity per unit correction factor of each organ studied, because we didn't calculate the correction factor of the organs. The accumulative 
activity per unit correction factor can be calculated through a graph of the relationship between the count and time residence time from the MIRD method used. The relationship graph between count and residence time involving many organs of source and target at once. In this case, the value of accumulative activity per unit correction factor is the area below the relationship graph between count and residence time, as shown in Figure 1 as follows [10]:

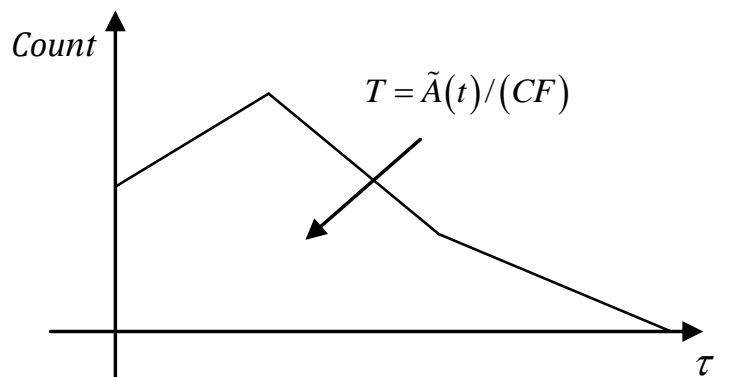

Fig. 1: Example of calculation for $T$ value from the area below the relationship graph between count and residence time involving many organs of source and target at once.

Once an accumulative activity value from 4 organs is calculated, absorption dose for each organ against radiopharmaceuticals injected into the blood can be known using formula (7). This formula can be elaborated into absorption dose per unit correction factor $D$ for each organ of heart, kidneys, thyroid, and liver, based on equation (11a) - (11d) as follows,

Heart : $D_{1}=T_{1} S(1 \leftarrow 1)+T_{2} S(1 \leftarrow 2)+T_{3} S(1 \leftarrow 3)+T_{4} S(1 \leftarrow 4)$.

Kidneys: $D_{2}=T_{1} S(2 \leftarrow 1)+T_{2} S(2 \leftarrow 2)+T_{3} S(2 \leftarrow 3)+T_{4} S(2 \leftarrow 4)$.

Thyroid : $D_{3}=T_{1} S(3 \leftarrow 1)+T_{2} S(3 \leftarrow 2)+T_{3} S(3 \leftarrow 3)+T_{4} S(3 \leftarrow 4)$.

Liver : $D_{4}=T_{1} S(4 \leftarrow 1)+T_{2} S(4 \leftarrow 2)+T_{3} S(4 \leftarrow 3)+T_{4} S(4 \leftarrow 4)$.

\section{Results and Discussion}

The research on accumulative activities was carried out on a patient who was identified as having breast cancer at Kariadi Hospital in Semarang Indonesia. This research uses oncology method and uses radiopharmaceuticals from Cobalt 57 MIDI with a dose of $20 \mathrm{mCi}$. Examination of MIRD at Kariadi Hospital aims to investigate the spread of breast cancer in organs around the breast organs by calculating the value of count and residence time on heart, thyroid, kidney and liverorgans. Residence time measurement is carried out in the hourly order for 5 measurements, namely at $0 ; 0.81 ; 1.14 ; 1.48$; and 1.96 hours on 4 organs studied.

In figure 2, the Count vs Time graph is described for four organs including heart, thyroid, kidney and liver. The accumulative activity per factor correction unit can be calculated of the Count vs Time graph as the sum of the area of the pentagonal which is bordered by the count axis, residence time axis and line equations.

By using $S$ factor value (table 1) and product values of count and time (hour) for 4 organs then we can be calculate absorption dose per unit correction factor $D$ using the equation (11) where the indexes of each organs 1, 2, 3 and 4 show an indexes for 4 organs. Table 2 shows the value of $T$ as a product of the count and time and the value of absorption dose per unit correction factor $D$, for various organs including 4 organs. The $D$ value is valid for the case from target organ $t$ to source organ $s(\mathrm{~s} \leftarrow \mathrm{t})$ or vice $\operatorname{versa}(\mathrm{t} \leftarrow \mathrm{s})$.

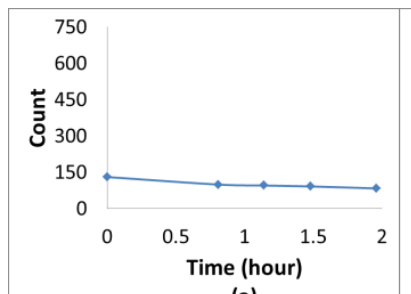

(a)

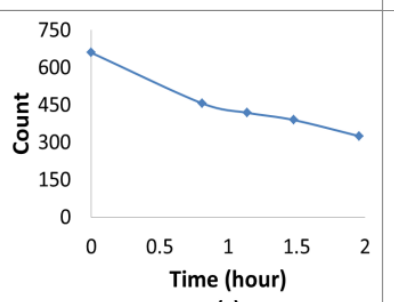

(c)

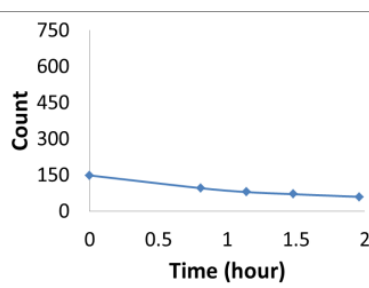

(b)

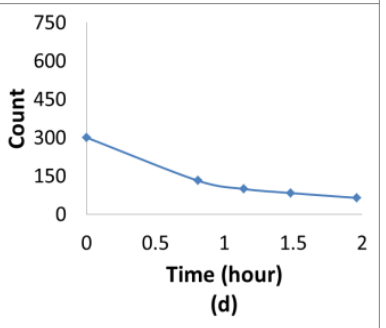

Fig. 2: Graph of the relationship between count vs time (hour) of 4 organs, namely a. heart, b. thyroid, c. kidney

and $d$. liver. The fourth graph above can be used to calculate the accumulative activity value of the 4 organs.

From table 2, we get the calculation of the value of absorption dose per unit correction factor $D$ for various organs with no significant difference between cases $(\mathrm{s} \leftarrow \mathrm{t})$ or $(\mathrm{t} \leftarrow \mathrm{s})$, so it can be considered the $\mathrm{D}$ value is not far between the two the case $(\mathrm{s} \leftarrow \mathrm{t})$ or $(\mathrm{t} \leftarrow \mathrm{s})$. The $D$ and $T$ values in table 3 are valid if the correction factors for all organs are considered to be the same. The largest $D$ value is obtained in the thyroid organ, and then followed by the kidney organ and finally the heart and liver organs.

Table 2: The value of $T$ (countxtime) and comparison factors of absorption dose to correction factor values from the four organs that include heart, thyroid, kidney and liver

\begin{tabular}{|l|l|l|l|l|}
\hline No & $\begin{array}{l}\text { The } \\
\text { Name } \\
\text { of } \\
\text { Organs }\end{array}$ & $\begin{array}{l}T \\
\text { count } \times \\
\text { time } \\
\text { (hour) }\end{array}$ & $D=\frac{\text { Absorption dose }}{\text { correction factor }}\left(\frac{\mathrm{rad} . \text { count }}{\mu \mathrm{Ci}}\right)$ \\
\hline 1. & Heart & 200,095 & $20.6(\mathrm{t} \leftarrow \mathrm{s})$ & $21.2(\mathrm{~s} \leftarrow \mathrm{t})$ \\
\hline 2. & Kidney & 906,055 & 173 & 174 \\
\hline 3. & Tyroid & 185,375 & 427 & 426 \\
\hline 4. & Liver & 278,725 & 17.1 & 165 \\
\hline
\end{tabular}

It appears from equation (11) that the factor $S$, based on table 1, was similarly made for each patient. However, if we carefully look at the formulation of the $\mathrm{S}$ factor from equation (5), it will likely be different for different patients. Therefore, Hidayati [5] did not use the table no. 11 of the MIRD, but used OLINDA / EXM software to calculate the $S$ value.

From the results of the above study, the highest absorption dose in patients indicated as having breast cancer is in the thyroid and kidney and then followed by the heart and liver. This study may have a difference in absorption dose with other studies of [4] because the correction factor values for each organ are made the same as well as the difference in the value of the $S$ factor used.

When it is compared with the results of Hersela's study [6], the absorbed doses for the thyroid and the kidney are the highest value to reach the order of $\mathrm{mGy}$, while the absorbed doses for the heart and the liver are in the order of $0.1 \mathrm{mGy}$, so the results of this 
study are not significantly different from the results of the previous study.

\section{Conclusion}

This study was conducted on patients who were identified as having breast cancer and were given an oncological medical treatment using the MIRD method by giving a Cobalt 57 MIBI of $20 \mathrm{mCi}$ dose. This oncology method is useful for diagnosing the spread of cancer cells to other body organs. However, it should be noted also about the level of absorption dose that may be received by the organs of the body so as not to endanger the body organs. The results showed that the highest uptake dose in these patients was in the thyroid and kidney organs, and then followed by the heart and liver. These results indicate that the thyroid and kidney organs are the most vulnerable organs affected by the continued negative effects of oncological therapy methods that inject radiopharmaceutical doses into the body of patients identified as a sufferer of breast cancer.

\section{Acknowledgment}

This work was financially supported by non-tax revenue (PNBP), Diponegoro University, Semarang, Indonesia under contract No. 1756 N/UN7.5.8/PG/2018.

\section{References}

[1] J. J. Bevelacqua, Internal Dosimetry Primer, Radiation Protection Management, Vol. 22 no. 5 (2005).

[2] J. Bucerius, H. Ahmazadehfar, and H-J. Biersack, Tc ${ }^{99 m_{-}}$-Sestamibi Clinical Application, (New Years: Springer Heidelberg Dordrecht London, 2012).

[3] N. Helal, Patient Organs Dose Calculations in Nuclear Medicine, IJRRAS 11,1 (2012).
[4] R.Suryanti, PenentuanDosis Internal Berbagai Organ Pada Pemeriksaan Bone Scan Tc99m MDP denganMetode MIRD, Tesis S2, Universitas Indonesia, Jakarta (2011).

[5] N. R. Hidayati, S. Setyowati, Sutari, Triningsih, Karyadi, S. Aguswarini, T. S. Humani, B. Hidayat, M. Ramli, S. Massora, V. Y. Susilo, A. Mutalib, H. Sastramihardja, and J. S. Masjhur. Studi Awal Estimasi Dosis Internal ${ }^{177}$ lu-Dota Trastuzumab Pada Manusia Berbasis Uji Biodistribusi pada Mencit, Indonesian Journal of Nuclear Science and Technology, Vol. 16, No. 2, 105-116 (2015).

[6] H. Hersela, Perhitungan nilai dosis internal denganmetode MIRD menggunakan Tc ${ }^{99 m}$ MIBI padaberbagai organ tubuh pasien kanker payudara pemeriksaan sidik onkologi, Skripsi program studi Fisika Departemen Fisika Undip, Juni (2018).

[7] W. S. Snyder, M. R. Ford, G. G. Warner, and S. B. Watson, "S", Absorbed Dose Per Unit Cumulated Activity for Selected Radionuclides and Organs, nm/mird Pamphlet no. 11, Oak Ridge National Laboratory, Oak Ridge, Tennesssee.

[8] W. E. Bolch, K. F. Eckerman, G. Sgouros, and S. R. Thomas, MIRD Pamphlet no. 21: A Generalized Schema for Radiopharmaceutical DosimetryStandardization of Nomenclature, J. Nucl. Med, 50, 477-484 (2009).

[9] K. S. Kolbert, T. Watson, C. Matei, S. Xu, J. A. Koutcher, and G. Sgouros, Murine S Factors for Liver, Spleen and Kidney, The Journal of Nuclear Medicine, Vol. 44 No. 5 (2003).

[10] M. G. Stabin, Internal Dosimetry in Nuclear Medicine, Brazilian Journal of Radiation Sciences, 01, 1-15 (2013). 